\title{
Correspondance
}

\section{Integrating medical and engineering undergraduate training}

A cademic programs that allow students to study core material from multiple subject areas in an integrated fashion have existed at North American medical schools for many decades and have included $\mathrm{MD} / \mathrm{PhD}, \mathrm{MD} / \mathrm{MBA}$ and $\mathrm{MD} / \mathrm{MPH}$ options. Interest in innovative programs to train potential clinical scientists, policy-makers and business leaders continues to be strong. ${ }^{1,2}$

Engineering with Medicine has been available since 1998 at the University of Western Ontario to students who are interested in combining expertise in engineering, mathematics, computing and the physical sciences with careers in clinical or academic medicine (Fig. 1). The dual MD/BESc program requires 7 years of study instead of the 8 that would be required to attain the degrees separately.

Students complete engineering coursework at the same time as they study the normal medical curriculum. They undertake a research-based thesis during the first 2 years of medical study. This thesis must demonstrate an application of engineering principles to current medical problems, and supervision is provided by members of both faculties. Projects have included a prototype apparatus to evaluate elbow joint mobility in-

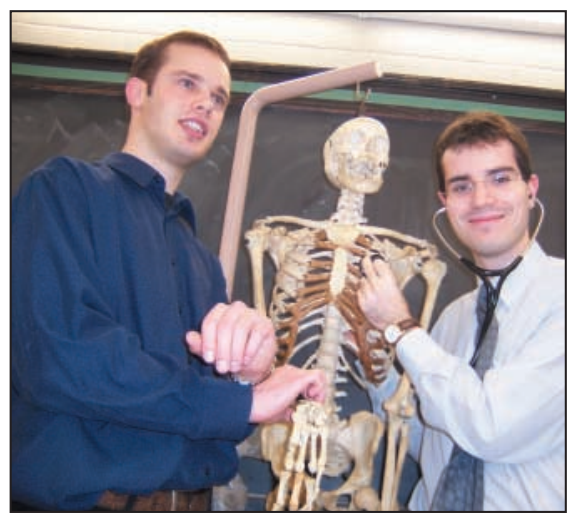

Fig. 1: Brent Lanting (left) and Joe Barfett (right) are students in the MD/BESc program at the University of Western Ontario. traoperatively and a microencapsulationbased artificial cell implant for drug delivery to the central nervous system.

Although the MD/BESc program is academically demanding, it offers several important advantages. Many engineering concepts such as transfer phenomena, thermodynamics and mechanical vibrations are studied in a more medical context than would be possible in a traditional engineering or physical sciences program. In addition, the simultaneous acquisition of engineering and clinical skills provides unique insights into ways that technology can be used to improve health care.

We hope that this program can serve as a model for the implementation of a similar curriculum at other institutions and welcome correspondence (jjbarfet@uwo.ca) concerning course structure and students' experiences.

\section{Joe Barfett}

Brent Lanting

MD/BESc Class of 2006

Argyrios Margaritis

Professor, Department of Chemical and Biochemical Engineering

\section{Carol Herbert}

Dean, Faculty of Medicine and Dentistry

Jim Silcox

Vice-Dean, Faculty of Medicine and

Dentistry

University of Western Ontario

London, Ont.

\section{References}

1. The physician-scientist: career issues and challenges at the year 2000. FASEB 7 2000;14:221-30.

2. The physician-scientist: an essential - and fragile - link in the medical research chain. $f$ Clin Invest 1999;103(12):1621-6.

DOI:10.1503/cmaj.045200

\section{Global IDEA}

$\mathrm{R}$ ecent CMAf commentaries ${ }^{1,2}$ have promoted the view that improved medical technologies are the most promising means of improving population health in developing countries. Although we support an increase in research into global health issues, we feel that clinical research into novel technical solutions will have less success in achieving improvements in population health than these commentaries suggest, for 3 reasons.

First, history shows that improvements in population health status in Western Europe have come largely in the absence of disease-specific control measures. The technologic improvements that coincided with large increases in life expectancy in the late 19th century related to improved sanitation, expanding access to safe water supplies and improvements in living conditions, not to specific medical interventions. ${ }^{3}$ Similarly, $90 \%$ of the reduction in mortality from tuberculosis in England and Wales predated the introduction of BCG (bacille Calmette-Guérin) vaccination or streptomycin. ${ }^{4}$

Second, in developing countries where significant improvements in population health have occurred in recent decades, other, so-called "upstream" determinants of health (such as female literacy $\left.{ }^{5,6}\right)$ appear to be more highly correlated with these changes. Developing countries that have achieved high levels of life expectancy and low levels of mortality, such as China, Sri Lanka and Cuba, have done so primarily because of investments in the social determinants of health (universal education, food subsidies) and a commitment to egalitarian principles.?

Third, the effectiveness of any clinical intervention in the community is always much less than that determined through clinical research, because of problems in health service access, diagnostic accuracy, and transport and management of supplies, among others. The oft-repeated example of vaccination is one of the few exceptions, likely because the intervention is relatively simple, needs to be applied only once or a few times, and does not need to target only those who are already ill.

Operational research is needed to assist developing countries in creating public policies that allow for the expansion of approaches already shown to have a greater impact than medical 
technology: access to safe drinking water, effective sanitation, safe housing, adequate nutrition (especially for women and children) and universal education. Furthermore, local health service research in low-income countries would greatly assist these countries to expand application of their current arsenal of effective health care interventions. Yes, developing countries have been neglected in terms of biomedical and clinical research into infectious diseases, but the technical knowledge needed to improved population health in developing countries already exists.

\section{David Moore \\ Robert Hogg}

BC Centre for Excellence in HIV/AIDS

Jerry Spiegel

Centre for International Health

University of British Columbia

Vancouver, BC

\section{References}

1. Global IDEA Scientific Advisory Committee. Health and economic benefits of an accelerated program of research to combat global infectious diseases [editorial]. CMA7 2004;171(10):1203-8.

2. Jha P, Lavery J. Evidence for global health [editorial]. CMA7 2004;170(11):1687-8.

3. Easterlin R. How beneficial is the market? A look at the modern history of mortality. Eur Rev Econ Hist 1999;3:257-94.

4. McKeown T. The role of medicine: dream, mirage or nemesis. Princeton (NJ): Princeton University Press; 1979.

5. Moore D, Castillo E, Richardson C, Reid RJ Determinants of health status and the influence of primary health care services in Latin America, 1990-98. Int 7 Health Plann Manage 2003;18: 279-92.

6. Black JA. The population Doomsday forecast: lessons from Kerala. 7 R Soc Med 1993;86:704-6.

7. Caldwell J. Routes to low mortality in developing countries. In: Caldwell J, Santow G, editors. Selected readings in the cultural, social and behav ioural determinants of health. Canberra, Australia: Highland Press; 1989.

DOI:10.1503/cmaj.1041727

W e applaud the recent informal assessment of the potential health and economic benefits that might flow from an accelerated program of research to combat global infectious diseases. ${ }^{1}$ The policies adopted for the organization and prioritization of health research should themselves, wherever possible, be evidence-based. ${ }^{2}$ However, many conceptual and empirical obstacles face those attempting retrospective analyses of economic benefits from spe- cific programs of health research; in particular, it is necessary to take full account of the cost of the contributing research and of its application, and to then assess the value of the incremental health and other benefits that follow. ${ }^{3}$

The proposal from the Global Infectious Disease Evidence and Analyses (Global IDEA) network ${ }^{1}$ refers to work from the United States on the economic benefits of health research ${ }^{4}$ that is rightly receiving considerable attention. In assessing returns in the context of the global debate about infectious diseases, however, one obvious problem is the value placed on the health gain. The US study valued the life of a US citizen at about $\$ 3$ million but even if that is the appropriate value to use in the US context, it is improbable that such a figure would be applied rationally by decisionmakers in other countries.

The Global IDEA Scientific Advisory Committee also argues that if $\$ 2$ billion is spent over 10 years for research on new tools that lead to a $5 \%$ increase in lives saved, this could, using figures from the important report from the Commission on Macroeconomics and Health, ${ }^{5}$ result in annual returns of about $\$ 9$ billion. We suggest that, in estimating the real return, it is essential to allow for the (possibly very substantial) costs of applying any new tools or technologies that result from the research. ${ }^{3}$

More work is needed to refine the methods for analyzing the payback from investments in health research. Initiatives such as the program proposed by Global IDEA might then be supported with firmer evidence of their possible benefit.

\section{Stephen R. Hanney \\ Martin J. Buxton}

Health Economics Research Group

Brunel University

Uxbridge, UK

\section{References}

1. Global IDEA Scientific Advisory Committee. Health and economic benefits of an accelerated program of research to combat global infectious diseases [editorial]. CMA7 2004;171(10):1203-8.

2. Hanney SR, Grant J, Wooding S, Buxton MJ. Proposed methods for reviewing the outcomes of health research: the impact of funding by the UK's 'Arthritis Research Campaign'. Health Res Policy Syst 2004;2:4. Available: www.health-policy-systems .com/content/pdf/1478-4505-2-4.pdf (accessed 2005 Jan 19).

3. Buxton M, Hanney S, Jones T. Estimating the economic value to societies of the impact of health research: a critical review. Bull World Health Organ 2004;82(10):733-9.

4. Murphy KM, Topel RH, editors. Measuring the gains from medical research: an economic approach. Chicago: University of Chicago Press; 2002.

5. World Health Organization. Macroeconomics and health: investing in health for economic development. Report of the Commission on Macroeconomics and Health. Geneva: The Organization; 2002.

DOI:10.1503/cmaj.1041726

\section{[Five members of the Global IDEA Scientific Advisory Committee respond to Dr. Moore and colleagues:]}

T ealth determinants are not neces1 sarily health interventions. Interventions need to be practicable (i.e., widespread use is possible) and affordable. We agree with David Moore and his colleagues that universal primary education has social returns beyond its impact on child and maternal survival. However, safe housing, sanitation and food subsidies are more costly and less practicable than are public health interventions. $^{1}$

As we have recently reviewed, ${ }^{2}$ research and the diffusion of knowledge have improved public health interventions (which differ from the more narrowly defined "medical" interventions), making them more efficacious and cheaper, which means that they are more cost-effective. Thus, mortality fell more rapidly in the 20th century than it fell in the 19th century. Access to vaccination and treatment of respiratory infections and diarrhea explain more of the decline in child mortality in India since 1975 than do differences in income growth or education. ${ }^{3,4}$ In rural Senegal, recent mortality decline can be traced to specific interventions, even in the absence of universal safe water, sanitation or housing. Smoking controls and changes in saturated fat intake have decreased adult mortality in Poland. ${ }^{6}$ (Declines in mortality due to tuberculosis before 1950 are a riddle. Although these declines were not due to antimicrobials, it is unclear if better living standards were responsible. Less well studied cofactors for tuberculosis may well have played a role.')

Interventions based on "egalitarian 